\title{
Grey Relational Analysis of the Correlation between the Road Transportation and the National Economy
}

\author{
Yong Zou ${ }^{1, \text { a }}$ \\ ${ }^{1}$ Chang'an university, Middle Section of Nan Erhuan Road, Xi'an City, Shannxi Province, 710064, \\ China
}

aemail: 281127573@qq.com

\begin{abstract}
Keywords: Road Transportation; National Economy; Correlation; Grey Relational Analysis
Abstract. In order to reveal the correlation between the road transportation industry and national economy in China from 1985 to 2013, the grey relational analysis method is chose to calculate the gray correlation degree between GDP as main performance index in national economy system and other four factors,such as passenger capacity,passenger person-kilometers, freight traffic,rotation freight ton-kilometers,as performance indexes in road transportation industry system. The result of calculation shows the correlation between road transportation industry and national economy in China has maintained at a high level and each factors in road transportation industry conforms the level of national economy development. The order of the correlation degree are easily illustrated by FT,PC,PPKs and RFTKs.It means FT is closer interactive with national economy than other factors in the period.
\end{abstract}

\section{Introduction}

The road transportation is the most widely used in the comprehensive transportation system, in which the road transportation features in its widest service scope, most carrying capacity, most flexible organizing methods, most various carrying products and most employees, and becomes one of most important pillars of national economic and social development. From the middle 80's of the last century, China's road transport industry began to carry out the industry reform. Until now the road transport industry has achieved a leap forward development, which results in the "bottleneck" of the national economy caused by road transportation industry having been almost eliminated and giving a strong support for the rapid development of economic society.

Many scholars, in the past decades, have made a qualitative and quantitative analysis on the relationship between transportation and national economic development.Chirenouzhu had qualitatively studied the relationships between transportation national economy in 2002[1], Chuan_ xu Wang had made a comprehensive evaluation of the coordinative effect of transportation and economy by the comprehensive weighted method. On such basis, a sensitivity analysis of the target weight and target value is given[2].

As a subindustry of transportation industry, the study on the relationship between the road transport industry and the national economy had been conducted by many professional researchers in past years. Lei Chen had analyzed the interactive relationship between the roadtransportation and the national economic development with panel data from Zhejiang province[3].Lifang Wang had established the evaluation index system and the evaluating model and conducted a analysis of adaptability of road transportation to the development of national economy based on road transportation supply-and-demand-balance coefficient, factors analysis and DEA model with Jilin province panel data[4].

This paper attempts to quantitatively analyze the relationship between the road transport industry and the whole national economy. By establishing index system of performance in road transportation industry and in national economic development, the grey relational analysis model is used to calculate in the paper. The results of calculation can provide the accurate data about interactive relationship between Road transportation industry system and national economy system. On the basis of those figures, paper further researches the reasons behind the performance and put forth a series of corresponding suggestions. 


\section{Calculation model and selection of performance indexes in two systems}

In this paper, the gray correlation analysis method is chose for the model of calculation. This method considers the "the gray correlation degree" which is based on the similarity or dissimilarity degree of development trend among factors is a measure of the degree of correlation between the two different systems. This method can be easily performed by SPSS software package.

The performance indexes in two different systems, road transportation industry and national economy,are selected as follows.Gross domestic production(GDP) is main performance index in national economy system and passenger capacity(PC), passenger person-kilometres(PPKs), Freight Traffic(FT), rotation volume of freight transport kilometres (RFTKs) are the performance indexes in road transportation industry.

\section{Collection of original data}

In order to better reveal the correlation between road transportation industry and national economy system, the paper collects the original data from year of 1985 to 2013. The period of data collection is nearly 30 years in order to lead to a thorough analysis. These original data which are presented in table 1 is originated from China Statistical Yearbook published by the China National Bureau of statistics[5].

Table 1 the original data from year of 1985 to 2013.

\begin{tabular}{|l|l|l|l|l|l|}
\hline year & GDP(100million) & PC(10Thousand) & $\begin{array}{l}\text { PPKs(100million } \\
\text { person_kilometers) }\end{array}$ & $\begin{array}{l}\text { FT(10thousand } \\
\text { ton) }\end{array}$ & $\begin{array}{l}\text { RFTKs(100million } \\
\text { ton_kilometers) }\end{array}$ \\
\hline 1985 & 9016 & 476486 & 1724.88 & 538062 & 1903.2 \\
\hline 1986 & 10275.2 & 544259 & 1981.74 & 620113 & 2117.99 \\
\hline 1987 & 12058.6 & 593682 & 2190.43 & 711424 & 2660.39 \\
\hline 1988 & 15042.8 & 650473 & 2528.24 & 732315 & 3220.39 \\
\hline 1989 & 16992.3 & 644508 & 2662.11 & 733781 & 3374.8 \\
\hline 1990 & 18667.8 & 648085 & 2620.32 & 724040 & 3358.1 \\
\hline 1991 & 21781.5 & 682681 & 2871.74 & 733907 & 3428 \\
\hline 1992 & 26923.5 & 731774 & 3192.64 & 780941 & 3755.39 \\
\hline 1993 & 35333.9 & 860719 & 3700.7 & 840256 & 4070.5 \\
\hline 1994 & 48197.9 & 953940 & 4220.3 & 894914 & 4486.3 \\
\hline 1995 & 60793.7 & 1040810 & 4603.1 & 940387 & 4694.9 \\
\hline 1996 & 71176.6 & 1122110 & 4908.79 & 983860 & 5011.2 \\
\hline 1997 & 78973 & 1204583 & 5541.4 & 976536 & 5271.5 \\
\hline 1998 & 84402 & 1257332 & 5942.81 & 976004 & 5483.38 \\
\hline 1999 & 89677.1 & 1269004 & 6199.2 & 990444 & 5724.3 \\
\hline 2000 & 99214.6 & 1347392 & 6657.4 & 1038813 & 6129.4 \\
\hline 2001 & 109655.2 & 1402786 & 7207.1 & 1056312 & 6330.4 \\
\hline 2002 & 120332.7 & 1475257 & 7805.8 & 1116324 & 6782.5 \\
\hline 2003 & 135822.8 & 1464335 & 7695.6 & 1159957 & 7099.5 \\
\hline 2004 & 159878.3 & 1624526 & 8748.4 & 1244990 & 7840.9 \\
\hline 2005 & 184937.4 & 1697381 & 9292.1 & 1341778 & 8693.2 \\
\hline 2006 & 216314.4 & 1860487 & 10130.8 & 1466347 & 9754.2476 \\
\hline 2007 & 265810.3 & 2050680 & 11506.8 & 1639432 & 11354.6872 \\
\hline 2008 & 314045.4 & 2682114 & 12476.1 & 2127834 & 371868.8969 .1861 \\
\hline 2009 & 340902.8 & 2779081 & 13511.4 & 2448052 & 43389.6721 \\
\hline 2010 & 401512.8 & 3052738 & 15020.8 & & \\
\hline & & & & & \\
\hline
\end{tabular}




\begin{tabular}{|l|l|l|l|l|l|}
\hline 2011 & 473104 & 3286220 & 16760.2 & 2820100 & 51374.7406 \\
\hline 2012 & 519470.1 & 3557010 & 18467.5 & 3188475 & 59534.9 \\
\hline 2013 & 56845.2 & 1853463 & 11250.9 & 3076648 & 55738.1 \\
\hline
\end{tabular}

\section{The progress of analysis}

The progress of analysis is divided into the following steps: nondimensionalization,the calculation of correlation coefficient and the calculation of the gray correlation degree.Whole original data mentioned in table 1 are nondimensionalized with z-score standard in the paper. Dimensionless data are showed in table 2.

Table 2 Dimensionless data

\begin{tabular}{|l|l|l|l|l|l|}
\hline Year & GDP & PC & PPKs & FT & RFTKs \\
\hline 1985 & -0.8960 & -1.1230 & -1.1498 & -1.0388 & -0.6505 \\
\hline 1986 & -0.8875 & -1.0459 & -1.0953 & -0.9175 & -0.6372 \\
\hline 1987 & -0.8753 & -0.9896 & -1.0511 & -0.7826 & -0.6036 \\
\hline 1988 & -0.8550 & -0.9249 & -0.9795 & -0.7517 & -0.5688 \\
\hline 1989 & -0.8418 & -0.9317 & -0.9511 & -0.7495 & -0.5592 \\
\hline 1990 & -0.8304 & -0.9276 & -0.9600 & -0.7639 & -0.5603 \\
\hline 1991 & -0.8092 & -0.8883 & -0.9067 & -0.7493 & -0.5559 \\
\hline 1992 & -0.7742 & -0.8324 & -0.8386 & -0.6798 & -0.5356 \\
\hline 1993 & -0.7170 & -0.6856 & -0.7309 & -0.5921 & -0.5161 \\
\hline 1994 & -0.6295 & -0.5794 & -0.6208 & -0.5113 & -0.4903 \\
\hline 1995 & -0.5438 & -0.4805 & -0.5396 & -0.4441 & -0.4773 \\
\hline 1996 & -0.4732 & -0.3880 & -0.4748 & -0.3798 & -0.4577 \\
\hline 1997 & -0.4201 & -0.2941 & -0.3407 & -0.3906 & -0.4416 \\
\hline 1998 & -0.3832 & -0.2340 & -0.2557 & -0.3914 & -0.4284 \\
\hline 1999 & -0.3473 & -0.2207 & -0.2013 & -0.3701 & -0.4135 \\
\hline 2000 & -0.2824 & -0.1315 & -0.1042 & -0.2986 & -0.3883 \\
\hline 2001 & -0.2114 & -0.0684 & 0.0123 & -0.2727 & -0.3759 \\
\hline 2002 & -0.1387 & 0.0141 & 0.1393 & -0.1840 & -0.3478 \\
\hline 2003 & -0.0334 & 0.0017 & 0.1159 & -0.1195 & -0.3282 \\
\hline 2004 & 0.1303 & 0.1840 & 0.3391 & 0.0062 & -0.2822 \\
\hline 2005 & 0.3008 & 0.2670 & 0.4543 & 0.1493 & -0.2293 \\
\hline 2006 & 0.5142 & 0.4527 & 0.6321 & 0.3334 & -0.1635 \\
\hline 2007 & 0.8510 & 0.6692 & 0.9238 & 0.5893 & -0.0642 \\
\hline 2008 & 1.1791 & 1.3881 & 1.1293 & 0.9993 & 1.2704 \\
\hline 2009 & 1.3618 & 1.4985 & 1.3487 & 1.3113 & 1.5385 \\
\hline 2010 & 1.7742 & 1.8101 & 1.6687 & 1.7847 & 1.9232 \\
\hline 2011 & 2.2612 & 2.0759 & 2.0374 & 2.3347 & 2.4185 \\
\hline 2012 & 2.5767 & 2.3842 & 2.3993 & 2.8792 & 2.9248 \\
\hline
\end{tabular}

With SPSS, all correlation coefficients are calculated and showed in table 3.

Table 3 correlation coefficients

\begin{tabular}{|l|l|l|l|l|}
\hline year & PC & PPKs & FT & RFTKs \\
\hline 1985 & 0.6709 & 0.6457 & 0.7650 & 0.6532 \\
\hline 1986 & 0.7456 & 0.6902 & 0.9418 & 0.6488 \\
\hline 1987 & 0.8032 & 0.7252 & 0.8345 & 0.6297 \\
\hline 1988 & 0.8707 & 0.7891 & 0.8187 & 0.6175 \\
\hline 1989 & 0.8388 & 0.8102 & 0.8353 & 0.6205 \\
\hline
\end{tabular}




\begin{tabular}{|l|l|l|l|l|}
\hline 1990 & 0.8278 & 0.7822 & 0.8764 & 0.6311 \\
\hline 1991 & 0.8558 & 0.8275 & 0.8876 & 0.6461 \\
\hline 1992 & 0.8905 & 0.8798 & 0.8320 & 0.6597 \\
\hline 1993 & 0.9392 & 0.9740 & 0.7885 & 0.6974 \\
\hline 1994 & 0.9047 & 0.9850 & 0.7977 & 0.7696 \\
\hline 1995 & 0.8818 & 0.9947 & 0.8241 & 0.8764 \\
\hline 1996 & 0.8462 & 1.0000 & 0.8337 & 0.9709 \\
\hline 1997 & 0.7869 & 0.8553 & 0.9430 & 0.9587 \\
\hline 1998 & 0.7569 & 0.7849 & 0.9859 & 0.9134 \\
\hline 1999 & 0.7862 & 0.7609 & 0.9561 & 0.8769 \\
\hline 2000 & 0.7548 & 0.7223 & 0.9694 & 0.8150 \\
\hline 2001 & 0.7648 & 0.6741 & 0.8851 & 0.7383 \\
\hline 2002 & 0.7524 & 0.6244 & 0.9134 & 0.6889 \\
\hline 2003 & 0.9323 & 0.7568 & 0.8447 & 0.6104 \\
\hline 2004 & 0.8982 & 0.6892 & 0.7896 & 0.5279 \\
\hline 2005 & 0.9347 & 0.7515 & 0.7541 & 0.4650 \\
\hline 2006 & 0.8847 & 0.7981 & 0.7194 & 0.4045 \\
\hline 2007 & 0.7184 & 0.8659 & 0.6385 & 0.3346 \\
\hline 2008 & 0.6890 & 0.9051 & 0.7205 & 0.8367 \\
\hline 2009 & 0.7729 & 0.9757 & 0.9039 & 0.7242 \\
\hline 2010 & 0.9307 & 0.8156 & 0.9812 & 0.7572 \\
\hline 2011 & 0.7144 & 0.6740 & 0.8649 & 0.7469 \\
\hline 2012 & 0.7065 & 0.7233 & 0.6042 & 0.5701 \\
\hline
\end{tabular}

In order to thoroughly analyze the interactive relationship between road transportation industry and National economy, the correlation coefficients in table 3 are visually diagrammed in figure 1 . In the figure 1,the trend of each factor are clearly showed.

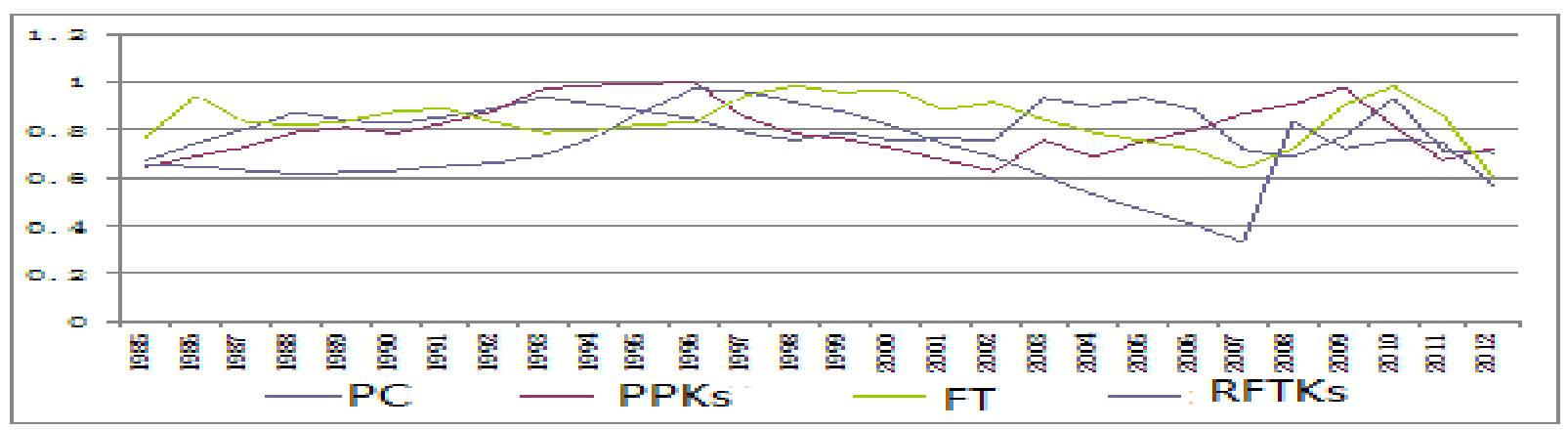

Fig. 1 the trend of each factor

Finally,on the basis of all Correlation Coefficients being calculated,the gray correlation degree between GDP and other factors,such as PC,PPKs,FT,RFTKs, are computed and listed in table 4.

Table 4 the gray correlation degree between GDP and other factors

\begin{tabular}{|c|l|l|l|l|}
\hline & PC & PPKs & FT & RFTKs \\
\hline the gray correlation degree & 0.8164 & 0.8029 & 0.8396 & 0.6925 \\
\hline
\end{tabular}

\section{Conclusions}

The result from the result of calculation shows the correlation between road transportation industry and national economy in China,from 1985 to 2013, has maintained at a high level and each factors in road transportation industry conforms the level of national economy development. The order of the 
correlation degree are easily illustrated by FT,PC,PPKs and RFTKs.It means FT is closer interactive with national economy than other factors in this period.

\section{References}

[1] Chirenouzhu: submitted to Journal of Tibet University (2002)

[2]Chuanxu Wang: submitted to Journal of Shanghai Maritime University (2000)

[3] Lei Chen: a dissertation submitted for the degree of master of Changan University(2007)

[4]Lifang Wang: a dissertation submitted for the degree of doctor of Jilin University(2005)

[5] Statistical Yearbook edited by National Bureau of Statistics. (1985-2013) 